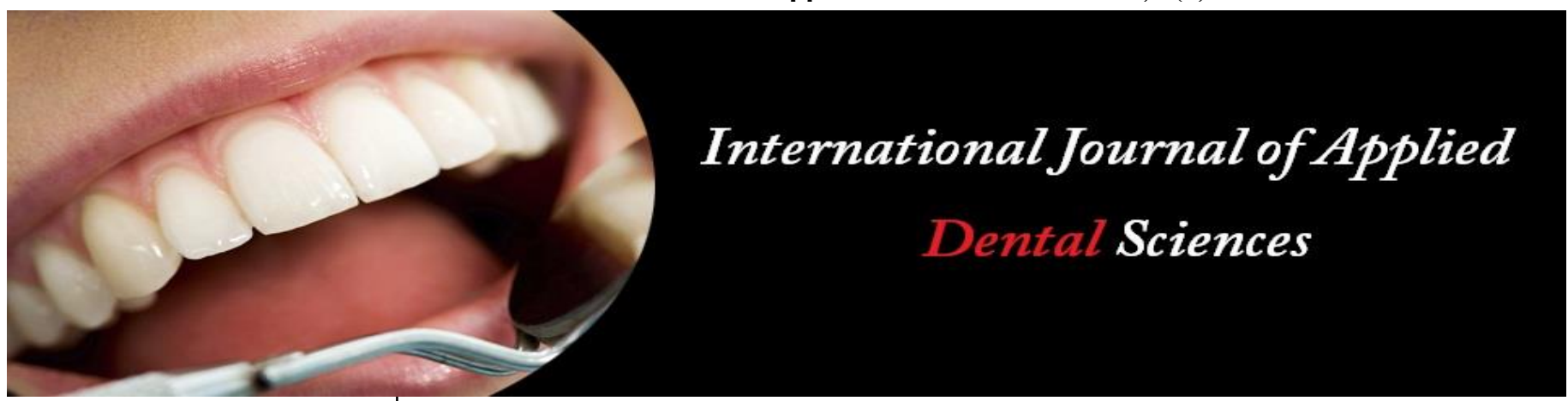

ISSN Print: 2394-7489

ISSN Online: 2394-7497

IJADS 2020; 6(4): 177-180

(C) 2020 IJADS

www.oraljournal.com

Received: 24-08-2020

Accepted: 25-09-2020

Priyanka Kashyap

Department of Paediatric

dentistry, Ahmedabad Dental

College \& Hospital, SP Ring Rd,

near Science city, Ahmedabad,

Gujarat, India
Corresponding Author:

Priyanka Kashyap

Department of Paediatric

dentistry, Ahmedabad Dental

College \& Hospital, SP Ring Rd, near Science city, Ahmedabad,

Gujarat, India

\section{Scardovia Wiggsiae - A new etiological agent for early childhood caries}

\section{Priyanka Kashyap}

DOI: $\underline{\text { https://doi.org/10.22271/oral.2020.v6.i4c.1064 }}$

\section{Abstract}

A new micro-organism has been found responsible for causing Early Childhood Caries (ECC) -Scardovia Wiggsiae (S.W). It belongs to a genus of unidentified Bifidobacterium. The existence of S.W should thus be counted along with S.Mutans and L.Bacilli. The active lesions of the caries had more S.W count than the non-caries when assessed. Also, it was seen that among those seeking orthodontic care, the incidence of S.W was greater. As S.W is one of the causative species for caries, it may be used as a risk marker for caries. To avoid ECC, we need to find ways to reduce the S.W count. One of the studies showed that incidence of caries can be decreased by using pit and fissure sealant. However, more research is required in this matter.

Keywords: Scardovia Wiggsiae, early childhood caries, Microflora

\section{Introduction}

Dental caries in the primary dentition, early childhood caries (ECC), is epidemic worldwide with a global prevalence burden of untreated caries of $8.8 \%{ }^{[1]}$ with increased levels in selected populations including 32\% very young (16-month-old) American Indian children with cavities [2]. A higher prevalence was observed for 3-year-olds, which ranged from 36 to $85 \%$ in the Asian countries of Taiwan, the Philippines and Korea ${ }^{[3]}$.

Most of the clinical studies referring to microbiology of ECC focuses on mutans streptococci (MS) and lactobacilli (LB), which are routinely detected using selective-culture-based methods ${ }^{[4]}$. However, the microbiota of biofilms taken from ECC patients has been acknowledged to contain a broad diversity of bacteria. Some studies support the view that caries can develop in the absence of MS ${ }^{[5-7]}$. Newer molecular methods have suggested that the traditional MS and LB species bear less significance, thereby giving clues that other species may also be responsible for ECC. Thus, several bacterial species, either alone or as a group, other than MS may also play major roles in caries development ${ }^{[5,8-10]}$.

\section{Microflora associated with ECC}

In children with ECC, studies have shown that Streptococcus mutans (S. mutans) frequently exceeds $30 \%$ of the microbial flora in the cultivable biofilm plaque ${ }^{[11-13]}$. Other species, identified with a lower percentage, belong to Veillonella, Granulicatella, Fusobacterium, Lactobacilli, Neisseria, Campylobacter, Gemella, Abiotrophia, Selenomonas and Capnocytophaga ${ }^{[4,14]}$.

Also, Actinomyces and Bifidobacterium were found to be associated with initial and deep caries, respectively ${ }^{[8,15]}$. In 2011, a study using anaerobic culture conditions allowed the identification of a newly named species, Scardovia wiggsiae (S.W) and Selenomonas noxia ${ }^{[16]}$, which was significantly associated with severe ECC. S.W was detected also in children without the contemporary presence of $S$. mutans, indicating its exclusive role in this disruptive process ${ }^{[17]}$. It was classified as an unidentified Bifidobacterium species, present within deep dentine caries and in high proportions within infected pulp tissue in children. Selenomonas noxia belongs to the Veillonella family, which has wide distribution among various animal species ${ }^{[18-20]}$. Apart from being found in the gastrointestinal tract, it is also found in the oral cavity and may be found in higher levels among patients with poor oral hygiene ${ }^{[21-24]}$. The 
most recent literature has shown a significant relationship between the presence of S.W in the early stages of caries and in pediatric subjects undergoing orthodontic therapy [25${ }^{28]}$. S.W has clinical importance in S-ECCs, being a potential risk indicator for the oral health of pediatric patients ${ }^{[29]}$.

\section{Association of S. Wiggsiae and S. Mutans with Caries}

Thomas et al. evaluated caries progression by studying demineralization of enamel chips worn in an intra-oral appliance ${ }^{[30]}$. S. mutans was found at higher levels in cariesactive than in caries-inactive subjects. In another study, Parascardovia denticolens was cultured from the forefront of carious lesions with vitally exposed pulps suggesting this Scardovia-related species was associated with lesion progression in dentin ${ }^{[31]}$. In another study, the major taxon cultured from deciduous pulps was S.W (Bifidobacterium $\mathrm{Ssp} 2$ was $S$. wiggsiae by $16 \mathrm{~S}$ rRNA sequences) ${ }^{[32]}$. In a pyrosequencing study, increased relative abundance of S.W was higher in dentin caries compared to caries-free sites or initial carious lesions ${ }^{[33]}$. Together these studies indicate an association of S.W and related taxa with dental caries and suggested that further study to examine cariogenic potential was indicated. Together these data on acid-production from Scardovia and Scardovia-related species indicate that they are strong acid producers, at a similar or greater extent than that of $S$. mutans. Further $S$. wiggsiae strains were arginine deaminase negative indicating the inability of this species to raise the $\mathrm{pH}$ from ammonia production.

\section{Metabolism of $S$. Wiggsiae}

Like Bifidobacterium species, S.W, via the F6PPK shunt, metabolizes sugars and produces acetic acid as an acidic endproduct. In the entire sequence of its genomes F0424, the gene sequences of two main F6PPK shunt enzymes, transaldolase and transketolase, have been assigned to help F6PPK shunt involvement in S. sugar metabolism. The F6PPK shunt is a metabolic pathway in which F6P is produced by glucose phosphorylation.

The enzymatic activities of transaldolase and transketolase are continually degraded until glycolysis via G3P eventually reaches the latter half and produces lactic and formic acids (lactate formate pathway) or is used to transform acetyl phosphate into acetic acid (acetate pathway). Besides acetic acid, S.W also developed small quantities of formic and lactic acids, suggesting that both above-mentioned pathways are used. At $\mathrm{pH} 7.0$, only acetic and formic acids were formed, while lactic acid was also formed at $\mathrm{pH} 5.5$ implying that there was a metabolic change in the lactate-formate pathway between lactic and formic acids ${ }^{[34]}$.

It has been documented that lactate dehydrogenase, which is responsible for the formation of lactic acid, acts under acidic conditions in oral streptococci, while pyruvate formate lyase is responsible for the function of formic acid production at neutral $\mathrm{pH}$ due to discrepancies between their optimum $\mathrm{pH}$ ${ }^{[35]}$. A previous study says that a higher proportion of acetic acid is non-ionized compared to lactic acid in low $\mathrm{pH}$ conditions, thus acetic acid is more likely to penetrate and decalcify enamel from within than lactic acid ${ }^{[36]}$. This implies that acetic acid-containing bacteria, S.W, cause caries to evolve and encourage the progression of caries.

S.W has high acid production and resistance to fluoride and lactic / acetic acid. It also has a distinctive metabolic pathway, F6PPK shunt, which by preserving the metabolic flow to the fluoride-tolerant acetic acid-pathway could contribute to its fluoride and acid tolerance.

\section{Isolation of S.Wiggsiae by RT-PCR}

One study assessed the levels of S.W in caries-free, early childhood caries (ECC) and severe ECC (SECC) affected children using real-time polymerase chain reaction (RT-PCR). Forty-five children aged $<71$ months were randomly recruited Fifteen children suffering from ECC, 15 with SECC, and 15 children without ECC were enrolled in the study. About 1-2 $\mathrm{mL}$ of unstimulated saliva was collected and subjected to microbial analysis using RT-PCR. The correlation of decayed, missing, or filled surface levels with 16s rRNA levels showed significant positive correlation with 16S rRNA in both ECC and S-ECC patients. They found that salivary levels of S.W were significantly associated with ECC in children ${ }^{[37]}$.

\section{Effect of sealant on S. Wiggsiae}

One of the study was done to evaluate the effect of sealant on the S.Wiggsiae count. It evaluated that placement of dental sealants was sufficient to reduce the levels of detectable Scardovia among those patients initially testing positive (23\%). However, most samples were initially Scardovianegative $(77 \%)$ and this study revealed a subset of these Scardovia-negative patients were subsequently found to harbor Scardovia from their corresponding post-sealant samples (28\%). Despite the change from S.W-negative to S.W-positive among some of the patients evaluated, these changes in the overall percentage of patients testing S.W positive were not large enough to be statistically significant [38].

\section{S. Wiggsiae count in caries risk assessment}

To evaluate the duration of periodic recall, a patient's caries condition is also used. A better caries-prediction tool will help to make preventive program more suitable for the individual. It will, however, be useful for patients and parents as an educational and motivational resource. A decrease in the number of microbes may represent the success of preventive care and encourage patients to continue their good long-term oral health practice.

The quest for the NCBI BLAST revealed that the nucleotide sequences of $S$. Wiggsiae-specific PCR products amplified from three samples of dental plaque showed a $100 \%$ match with S.W strain F0424 and some other Bifidobacteria have a partial match. In both dental plaque and dentine samples, S.W was found, but its proportion was lower than S. mutans. The incidence of both microbes was substantially higher in the ECC group than in the caries-free group in dental plaque samples.

Thus, the plausibility of applying $S$. wiggsiae as a microbiological marker in combination with $S$. mutans, for better caries risk assessment in children will give positive predictive value for caries. However, using single microorganism detection appears to compromise the sensitivity or specificity of the tests ${ }^{[39]}$.

\section{Orthodontics and $S$. Wiggsiae}

The discrepancy between orthodontic and non-orthodontic patients was examined for the count of S.W associated with white spot lesions in one of the retrospective studies. This research selected more than one hundred saliva samples from adult orthodontic $(n=49)$ and non-orthodontic $(n=52)$ patients for inclusion. Subsequently, all DNA derived from these samples was analyzed using PCR, which indicated the presence of $S$. P. gingivalis (PG), S. mutans (SM), and $S$. 
Wiggsiae (S.W), the prevalence of which varied between nonorthodontic and orthodontic patients. Nearly all the PGpositive and S.W-positive tests were also SM-positive in nonorthodontic patients. None of the S.W-positive samples were either SM- or PG-positive among orthodontic patients, however. In patients seeking orthodontic therapy, this indicates the S.W is prevalent. Thus, it will not be wrong to say that the associationn of S.W with white spot lesions can lead to early cavitation ${ }^{[40]}$.

\section{Conclusion}

$S$. wiggsiae represents a new frontier in the microbial etiology of ECC. This may lead to the development of new antimicrobial agents targeted to this organism and change in practices. Like in treatment of ECC it was found that using pit and fissure sealant would lead to reduction in its count. Also, new strategies must be formulated to prevent the growth of $S$. wiggsiae along with the other micro-organisms leading to cavitation.

\section{References}

1. Kassebaum NJ, Bernabe E, Dahiya M, Bhandari B, Murray CJ, Marcenes W. Global burden of untreated caries: a systematic review and metaregression. J Dent Res 2015;94:650-8.

2. Warren JJ, Kramer KW, Phipps K, Starr D, Dawson DV, Marshall T, Drake D. Dental caries in a cohort of very young American Indian children. J Public Health Dent 2012;72:265-8.

3. Colak H, Dulgergil CT, Dalli M, Hamidi MM. Early childhood caries update: A review of causes, diagnoses, and treatments. J Nat Sci Biol Med 2013;4:29-38.

4. Li Y, Tanner A. Effect of antimicrobial interventions on the oral microbiota associated with early childhood caries. Pediatr Dent 2015;37:226-44.

5. Takahashi N, Nyvad B. Caries ecology revisited: Microbial dynamics and the caries process. Caries Res 2008;42:409-18.

6. Aas JA, Griffen AL, Dardis SR, Lee AM, Olsen I, Dewhirst FE et al. Bacteria of dental caries in primary and permanent teeth in children and young adults. J Clin Microbiol 2008;46:1407-17

7. Bowden GH. Does assessment of microbial composition of plaque/saliva allow for diagnosis of disease activity of individuals? Community Dent Oral Epidemiol 1997;25:76-81

8. Van Houte J, Lopman J, Kent R. The final pH of bacteria comprising the predominant flora on sound and carious human root and enamel surfaces. J Dent Res 1996;75:1008-14

9. Sansone C, Van Houte J, Joshipura K, Kent R, Margolis HC. The association of mutans streptococci and nonmutans streptococci capable of acidogenesis at a low $\mathrm{pH}$ with dental caries on enamel and root surfaces. J Dent Res 1993;72:508-16.

10. Van Houte J. Role of micro-organisms in caries etiology. J Dent Res 1994;73:672-81.

11. Van Houte J, Gibbs G, Butera C. Oral flora of children with "nursing bottle caries". J Dent. Res. 1982;61:382385.

12. Berkowitz RJ, Turner J, Hughes C. Microbial characteristics of the human dental caries associated with prolonged bottle-feeding. Arch. Oral Biol 1984;29:949951.

13. Parisotto TM, Steiner-Oliveira C, Silva CM, Rodrigues
LK, Nobre-dos-Santos M. Early childhood caries and mutans streptococci: A systematic review. Oral Health Prev. Dent 2010;8:59-70.

14. Peterson SN, Meissner T, Su AI, Snesrud E, Ong AC, Schork NJ et al. Functional expression of dental plaque microbiota. Front. Cell. Infect. Microbiol 2014;4:108.

15. Becker MR, Paster BJ, Leys EJ, Moeschberger ML, Kenyon SG, Galvin JL et al. Molecular analysis of bacterial species associated with childhood caries. J Clin. Microbiol 2002;40:1001-1009.

16. Downes J, Mantzourani M, Beighton D, Hooper S, Wilson MJ, Nicholson A et al. Scardovia wiggsiae sp. nov., isolated from the human oral cavity and clinical material, and emended descriptions of the genus Scardovia and Scardovia inopinata. Int. J Syst. Evol. Microbiol 2011;61:25-29.

17. Tanner AC, Mathney JM, Kent RL, Chalmers NI, Hughes CV, Loo CY et al. Cultivable anaerobic microbiota of severe early childhood caries. J Clin. Microbiol. 2011;49:1464-1474.

18. Tanner A, Bouldin HD, Maiden MF. Newly delineated periodontal pathogens with special reference to Selenomonas species. Infection 1989;17(3):182-7.

19. Kolenbrander PE, Andersen RN, Moore LV. Coaggregation of Fusobacterium nucleatum, Selenomonas flueggei, Selenomonas infelix, Selenomonas noxia, and Selenomonas sputigena with strains from 11 genera of oral bacteria. Infect Immun. 1989;57(10):3194-203.

20. Maiden MF, Tanner A, Moore WE. Identification of Selenomonas species by whole-genomic DNA probes, sodium dodecyl sulfate-polyacrylamide gel electrophoresis, biochemical tests and cellular fatty acid analysis. Oral Microbiol Immunol 1992;7(1):7-13.

21. Tanner A, Kent R, Maiden MF, Taubman MA. Clinical, microbiological and immunological profile of healthy, gingivitis and putative active periodontal subjects. J Periodontal Res 1996;31(3):195-204.

22. Socransky SS, Haffajee AD, Cugini MA, Smith C, Kent RL Jr. Microbial complexes in subgingival plaque. J Clin Periodontol 1998;25(2):134-44.

23. Boström L, Bergström J, Dahlén G, Linder LE. Smoking and subgingival microflora in periodontal disease. J Clin Periodontol 2001;28(3):212-9.

24. Ledezma-Rasillo G, Flores-Reyes H, Gonzalez-Amaro AM, Garrocho-Rangel A, del Socorro Ruiz-Rodriguez M, Pozos-Guillen AJ. Identification of cultivable microrganisms from primary teeth with necrotic pulps. J Clin. Pediatr. Dent 2010;34:329-333.

25. Tanner AC, Sonis AL, Lif Holgerson P, Starr JR, Nunez Y, Kressirer CA et al. White-spot lesions and gingivitis microbiotas in orthodontic patients. J Dent. Res. 2012; 91:853-858.

26. Streiff BJ, Seneviratne M, Kingsley K. Screening and prevalence of the novel cariogenic pathogen scardovia wiggsiae among adult orthodontic and non-orthodontic patient saliva samples. Int. J Dent. Oral Health. 2015;1:16.

27. Reyes N, Pollock A, Whiteley A, Kingsley K, Howard K. Prevalence of Scardovia wiggsiae among a pediatric Orthodontic patient population. EC Dent. Sci. 2017;2:203-210.

28. Kressirer CA, Smith DJ, King WF, Dobeck JM, Starr JR, Tanner ACR. Scardovia wiggsiae and its potential role as a caries pathogen. J Oral Biosci. 2017;59:135-141. 
29. Larsen T, Fiehn NE. Dental biofilm infections-An update. APMIS 2017;125:376-384.

30. Thomas RZ, Zijnge V, Cicek A, de Soet JJ, Harmsen HJ, Huysmans MC. Shifts in the microbial population in relation to in situ caries progression. Caries Res. 2012;46:427-31.

31. Chalmers NI, Oh K, Hughes CV, Pradhan N, Kanasi E, Ehrlich Y, Dewhirst FE, Tanner AC. Pulp and plaque microbiotas of children with severe early childhood caries. J Oral Microbiol 2015;7:25951.

32. Ledezma-Rasillo G, Flores-Reyes H, Gonzalez-Amaro AM, Garrocho-Rangel A, del Ruiz-Rodriguez MS, Pozos-Guillen AJ. Identification of cultivable microorganisms from primary teeth with necrotic pulps. J Clin Pediatr Dent. 2010;34:329-33.

33. Jiang $\mathrm{W}$, Ling Z, Lin X, Chen $\mathrm{Y}$, Zhang J, Yu J et al. Pyrosequencing analysis of oral microbiota shifting in various caries states in childhood. Microb Ecol. 2014;67:962-9.

34. Kameda M, Abiko Y, Washio J, Tanner AC, Kressirer CA, Mizoguchi I, Takahashi N. Sugar Metabolism of Scardovia wiggsiae, a Novel Caries-Associated Bacterium. Frontiers in Microbiology. 2020;11:479

35. Iwami Y, Abbe K, Takahashi-Abbe S, Yamada T. Acid production by streptococci growing at low $\mathrm{pH}$ in a chemostat under anaerobic conditions. Oral Microbiol. Immunol. 1992;7:304-308. doi: 10.1111/j.1399-302x.1992.tb00593.

36. Hoppenbrouwers PM, Driessens FC. The effect of lactic and acetic acid on the formation of artificial caries lesions. J Dent. Res. 1988;67:1466-1467. doi: 10.1177/00220345880670120501

37. Chandna P, Srivastava N, Sharma A, Sharma V, Gupta $\mathrm{N}$, Adlakha V. Isolation of Scardovia wiggsiae using real-time polymerase chain reaction from the saliva of children with early childhood caries. Journal of the Indian Society of Pedodontics and Preventive Dentistry. 2018;36(3):290-5.

38. Quan K, Kingsley K. Effect of Dental Sealants on Oral Microbial Burden of Scardovia wiggsiae within a Pediatric Population: A Pilot Study. Microbiology Research Journal International, 2018, 1-0.

39. Vacharaksa A, Suvansopee P, Opaswanich N, Sukarawan W. PCR detection of Scardovia wiggsiae in combination with Streptococcus mutans for early childhood caries-risk prediction. European journal of oral sciences 2015;123(5):312-8.

40. Streiff BJ, Seneviratne M, Kingsley K. Screening and prevalence of the novel cariogenic pathogen scardovia wiggsiae among adult orthodontic and non-orthodontic patient saliva samples. International Journal of Dentistry and Oral Health 2015;1(6):1 